\title{
MOROS POR INDIOS: ENSAYANDO UNA LECTURA EX-CÉNTRICA DEL DISCURSO COLONIAL EN LA MANGANILLA DE MELILLA DE JUAN RUIZ DE ALARCÓN
}

POR

\author{
Alberto Sandoval-SáncheZ \\ Mount Holyoke College
}

Para Mabel Moraña

Fuera de algunos profesores de filología que reciben un salario por ello, no hay más que un tipo de hombre que conozca de veras, en su conjunto, la literatura europea: el colonial (Roberto Fernández Retamar 60)

¿Por qué la crítica dominante del teatro barroco español no ha leído en las comedias de Juan Ruiz de Alarcón el discurso colonial de un indiano asimilado? ¿Por qué se ha notado un cierto distanciamiento, una diferencia y una actitud crítica en sus comedias hacia la sociedad aristocrática española de comienzos del siglo XVII, mas, siempre dejándose de lado la página en blanco en lo referente a su condición colonial y en lo de explicar su singularidad como dramaturgo? ¿Por qué se ha silenciado esa aprehensión particular de Ruiz de Alarcón como una simple "extrañeza"?" ¿No es acaso esa diferencia la vivencia testimonial e ideológica de un forastero venido de la Nueva España, de un colono pretendiente y pobre metido en el mismo centro cortesano, y un indicio de cierta modalidad de extranjería, producto/producción en sus comedias de una mirada crítica, propia del que viene de afuera? ¿No es también acaso la visión de mundo de un colono dramaturgo que, desde el margen, escribe para el mismo centro imperial?

$\mathrm{Me}$ arriesgo a afirmar que esa negación, mutismo e indiferencia de los críticos europeos y anglo-americanos hacia la condición colonial alarconiana se debe a la falta de referencialidad de lo singularmente indígena en la propia persona de este dramaturgo y también a la ausencia del signo amerindio en la estructura superficial de sus comedias. Desde la canonización de Ruiz de Alarcón en el siglo XIX, esa ausencia referencial condujo a los filólogos españoles a leer las obras de este dramaturgo a imagen y semejanza de sí

Quisiera expresar mi gratitud a Luis Felipe Díaz por su lectura cuidadosa de este ensayo y por sus correcciones estilísticas.

1 Tal "extrañeza" proviene del comentario de Juan Pérez de Montalbán en Para Todos en 1632 sobre las comedias de Ruiz de Alarcón: “... las dispone con tal novedad, ingenio, y extrañeza, que no hay comedia suya que no tenga mucho que admirar y nada que reprender" (XVI). Citado por Juan E. Hartzenbusch. 
mismos. Esa omisión de su condición indígena y mestiza que va de la mano con la escasez de alusiones a la topografía novohispana en las comedias es, por ende, el vacío referencial del que se valen los críticos para españolizar a Ruiz de Alarcón, y, en palabras de Don Marcelino Menéndez y Pelayo, para hacerlo "americano españolizado" (LVIII). Ya que no se puede evidenciar la presencia de sangre indígena en su parentesco, ni presenciamos los indios con plumas en sus comedias, ¿dónde, entonces podemos buscar su diferencia colonial? Es evidente que esa carencia de autoctonía colonial es el factor que facilita su incuestionable colocación dentro del ambiente cortesano madrileño de 1600 . Y aunque resulte paradójico es precisamente esa ausencia lo que hace posible su inserción en el canon peninsular y es lo que lo lleva en su teatro a apoyar, sostener y justificar su condición de colono asimilado, de noble venido a menos, pobre y jorobado. ${ }^{2}$

No hay duda de que la ausencia del referente indio en su propia persona, y el hecho de que él mismo silenciara ese referente en su escritura, ubicándose así en el abismo de la nosignificación/in-significación, favoreció la canonización de Ruiz de Alarcón en España desde mediados del siglo diecinueve y su inclusión como dramaturgo del teatro clásico peninsular en los departamentos de español en los Estados Unidos en la segunda mitad del siglo veinte. A pesar de la obvia y reiterada "extrañeza" alarconiana, la motivación ideológica por la que los canonizadores han integrado al dramaturgo en el ámbito peninsular del teatro barroco puede explicarse con la siguiente proposición teórica de Gayatri Spivak: "the putative center welcomes selective inhabitants of the margin in order better to exclude the margin. And it is the center that offers the official explanation; or, the center is defined and reproduced by the explanation that it can express" (107). Ésta fue la postura ideológica de marginado que se le impusiera a Ruiz de Alarcón y que iniciara Menéndez y Pelayo en su Antología de poetas hispanoamericanos al excluir al dramaturgo por la "ausencia de color americano" y por "salirse del marco de la poesía colonial":

Varias razones nos inducen á prescindir de Alarcón en este estudio. Es la primera la total ausencia de color americano que se advierte en sus producciones, de tal modo, que si no supiéramos su patria, nos sería imposible adivinarla por medio de ellas. Es la segunda su propia grandeza y perfección como dramático, la cual le hace salirse del marco de la poesía colonial, que resulta exiguo y desproporcionado para tal figura (LIX).

La mirada imperial de Mendéndez y Pelayo, aún con ínfulas imperialistas en 1892, lo traiciona al proponerse buscar el "color americano". No sólo presume de definir el espacio canónico de las letras coloniales americanas sino que él mismo apela a una concepción estereotipada de América como espacio de colorido y pintoresco, de animación o viveza exótica, que por adyacencia metonímica colinda con el color racial de los indios. Ese colorido local, le permite colocar a la raza indígena con sus plumas y exotismo dentro de los estereotipos dominantes de la otredad racial, existentes desde el Descubrimiento y la Conquista del Nuevo Mundo en la mentalidad europea. Debido, además, a la ausencia del indio en la superficie de los textos dramáticos alarconianos, se efectúa una lectura superficial imperialista que elimina toda posible articulación y toma de posición de un sujeto

${ }^{2}$ En "Aportes para una canonización de Juan Ruiz de Alarcón" estudio el proceso de canonización del dramaturgo en España y Latinoamérica. 
colonial alarconiano que contendría y remitiría a su propia experiencia de colono asimilado. $\mathrm{Y}$ esto, en consecuencia, es factor que facilita su inclusión definitiva en el canon de las letras latinoamericanas.

Aunque Menéndez y Pelayo bien sabe cuál es la "patria" —el lugar de origen-, se excusa de tener que explicar la condición colonial de Ruiz de Alarcón, señalando la imposibilidad de adivinarla por medio de sus obras. Su aseveración posibilita irrefutablemente la inserción de Ruiz de Alarcón en el canon peninsular sin tener que explicar su origen. El centro, como indicó Spivak, selecciona y excluye, según sus normas y horizonte de expectativas, aquello que es de calidad y de valor estético en la poesía colonial. La explicación oficial, a su vez, posibilita establecer la superioridad de la escritura imperial colocándose así al dramaturgo (y la poesía colonial) en una categoría inferior. ${ }^{3}$ Pero, el proceso de recuperación de Ruiz de Alarcón no es tan simple para Menéndez y Pelayo y su buen ojo crítico imperialista, pues, una vez que se apropia del dramaturgo tiene que reconocer la diferencia de la producción dramática de éste, al verlo sobresalir por su exceso y al imponerlo por encima de las letras coloniales. Ruiz de Alarcón, en este sentido, se desborda, se "sale del marco", cruza fronteras. Por ende, su "grandeza y perfección" no se compara a la producción insignificante, "exigu[a] y desproporcionad[a]", según el crítico, de la poesía colonial. Desde esta posición de autoridad y autoritaria, sólo es permisible leer a Ruiz de Alarcón desde el centro - por y para el centro discursivo imperial y oficial - sin tener que acudir a una explicación de su situación de colono.

Otro crítico español, Angel Valbuena Prat, alude mediante la metáfora del indio, ausente en las obras de Ruiz de Alarcón, a la condición colonial de éste. Entrevé, este crítico, al indio con plumas asomándose en la escritura alarconiana:

Alarcón asoma a su 'comedia moral', la cautela del indio, una sinuosidad de raza semimongólica, una habilidad de 'extrañeza' ante la corte ... (Historia del teatro, 200).

La sinuosidad india de Alarcón nos puede llevar a laberintos de difícil comprensión literal. Raza, ambiente, junto al caso sicológico individual del deforme físico, determinaban una actitud de resentimiento ... (Historia de la literatura, 504).

Frente a esta actitud de ignorancia moldeada por los estereotipos raciales etnocéntricos y eurocéntricos, queda articulada la invención o ficcionalización de una raza para Ruiz de Alarcón. Ya en 1913 Pedro Henríquez Ureña en su conferencia "Don Juan Ruiz de Alarcón", también había aludido a la naturaleza y sicología del indio en la obra del dramaturgo, en su esfuerzo por instalarlo en el canon de las letras coloniales latinoamericanas:

Y por último, hay una virtud de tercer orden que estimaba en mucho: la cortesía. Vosotros, quizá, extrañaréis se os diga que ésta es muy de México; pero yo, que no nací aquí, sé lo

\footnotetext{
${ }^{3}$ Menéndez y Pelayo coloca toda la producción literaria latinoamericana dentro de patrones eurocéntricos con lo que perpetúa una relación de dominio imperial y escritura oficial: "[la literatura hispano-americana] ha seguido en todo las vicisitudes de la general literatura espanola, participando del Clasicismo italiano del siglo XVI, del Culteranismo del XVII, de la reacción neoclásica del XVIII, del Romanticismo del presente y de las influencias de la novísima literatura extranjera, especialmente de la francesa y de la inglesa" (15).
} 
que es. Acaso la cortesía mexicana, en buena parte, haya recibido influencia de la cortesanía indígena. Ésta era proverbial precisamente en los tiempos de nuestro dramaturgo: 'cortés como un indio mexicano' dice en el Marcos de Obregón Vicente Espinel (16).

Tanto para Valbuena Prat como para Henríquez Ureña, raza y nación mejicana convergen en la persona inventada y en la escritura diferencial de Ruiz de Alarcón. La vinculación con el indio se posibilita a través del establecimiento de la psicología racial y del carácter nacional inscritos en el mapa cultural, social y nacional de México. El indio, configurado como la otredad diferencial que se distingue por su "cautela", "sinuosidad" y "cortesía", pasa a constituir en la escritura del dramaturgo las características de una comunidad racial imaginada.

Si se considera hasta qué punto "cautela" y "cortesía" funcionan como modos de comportamiento y estrategias de sobrevivencia para el indio en el sistema imperial de la Colonia, entonces, ¿cómo se podrían aplicar a Ruiz de Alarcón tal "cautela" y "cortesía"? Por lo visto, entre líneas los críticos descifran inconscientemente una serie de tácticas y estrategias en la escritura de Ruiz de Alarcón que articulan una posición diferencial, de alguien que se mueve con cuidado, que se guarda, que mide las palabras, que disimula, que utiliza medios indirectos, que oculta el fin en que se percibe. Es ahí, de hecho, donde los críticos detectan una conciencia diferenciadora de un colono que escribe desde afuera para un centro imperial. Mas cabe advertir que ese cuidado de Ruiz de Alarcón es pura apariencia por su afán de no descubrir su secreto: el de ser (escritor) de la colonia. Ruiz de Alarcón silencia y se cuida de que su escritura no registre una discursividad y retórica colonial que denunciaría su situación de colono y lo colocaría fuera del marco de la poesía imperial.

Ahora bien, volviendo a Henríquez Ureña, a pesar de la nota sobrecargada de nacionalismo en su reivindicación de Ruiz de Alarcón, hay que reconocer que planteó con exactitud la condición diferencial y colonial del dramaturgo: "Alarcón llevó al teatro español caracteres singulares que en parte dependen de su origen criollo ... su condición de mexicano, hijo del país colonial" ("El Teatro", 715). Henríquez Ureña se sirve del nacionalismo mexicano para suplir el vacío del indio o del mestizo como factor determinante que facilitaría la canonización inevitable de Ruiz de Alarcón en las letras coloniales americanas. Pero, el crítico no se da del todo por vencido en su afán por ubicar al dramaturgo en el contexto amerindio colonial de las letras americanas. Para compensar la ausencia del indio, se refiere a la formación social del dramatugo colocándolo a la par con el Inca Garcilaso. Procura Henríquez Ureña así vincularlos por contigüidad y continuidad geográfico-espacial del continente y por la conexión racial tanto ausente —en un casocomo presente - en el otro-que los diferencia y que los asemeja mediante la invención de una raza: "Juan Ruiz de Alarcón no tuvo, que sepamos, ningún antepasado indígena: pero, como Garcilaso, creció dentro de la nueva sociedad de la América hispánica, y su obra muestra, sutilmente, la influencia de su medio nativo" (Las corrientes literarias, 71). No hay duda de que aquí "nativo" se refiere a ser natural de Indias, o amerindio. Volvemos con estos criterios, una vez más, a la relación de raza y nación para definir las letras coloniales (y las letras americanas). Ruiz de Alarcón vuelve, así, a escurrirse, a deslizarse en el no ser ni esto ni lo otro, en no ser ni indio ni español. En otras palabras, Ruiz de Alarcón complica y problematiza el panorama de la identidad colonial ya que como indiano asimilado en su 
persona no se puede aplicar una simple categorización de diferencia racial, ni tampoco se puede adjudicar una categoría de identidad criolla o de nación en un momento histórico en que no se había gestado aún una conciencia emancipadora en América. Por eso, los críticos vuelven siempre al punto de origen para constatar la diferencia alarconiana sin nunca poder articular, expresar y configurar en qué consiste su condición colonial:

... la cuestión no está en el color local ni en el número de citas a Indias, sino algo más hondo en que se refleja el alma intima, el paisaje espiritual de su tierra de origen ... (Valbuena Prat, Historia de la literatura, 512).

Obviamente, si la cuestión no está en el color local ni en el número de citas sobre las Indias, hay que plantearse entonces cómo a nivel ideológico y cultural en las estructuras profundas de los textos de Ruiz de Alarcón se produce una identidad y modalidad discursiva y retórica coloniales. Y esto habría que verlo junto al hecho de que en la estructura superficial sus textos se amoldan a las exigencias del discurso imperial. Resulta también necesario plantearse cuál es la posición y re-presentación del sujeto autorial alarconiano en las coyunturas y redes discursivas coloniales dentro de las fases hegemónicas del imperialismo español de 1600.

Para proseguir, pues, con una lectura alternativa que descifre el discurso colonial alarconiano, permítaseme recurrir a una digresión de Rosario Castellanos, que enfoca la situación colonial del hablar y del mutismo en el sujeto colonial del siglo XVII:

[Ruiz de Alarcón] Escribe dramas porque quiere romper su mutismo y hablar por la boca de sus protagonistas; porque quiere abandonar el ademán de cortés asentimiento que se adjudica como propio a los indianos, y entablar el diálogo con la gente. Un diálogo que en América topaba con el silencio mineral del indio, con la media voz ambigua del mestizo, con la arrogancia estetórea del criollo, y que en la Metrópoli tenía que imponerse sobre el estrépito gradilocuente de los autores (152).

Castellanos resume esas voces e identidades coloniales silenciadas, híbridas o subversivas que quieren hablar y ser oídas. Para ella, Ruiz de Alarcón refracta este conjunto de voces controladas y subyugadas por la superimposición lingüistica imperial que definen la diferencia del sujeto colonial subalterno y que no le permite expresarse más que en y desde una posición de sujeto asignada y fijada en y por el discurso imperial dominante. Mas, este comentario da luz al discurso y a la voz del sujeto colonial que habla en silencio por entre medio de los intersticios del poder imperial: haciendo interrupciones, valiéndose de mediaciones y de desplazamientos metafóricos. ${ }^{4}$ Sin embargo, para ese sujeto colonial a principios de 1600 aún no se ha articulado, construido y configurado una toma de posición de subjetividad propia. Ahora bien, Castellanos capta (quizás justamente por ser mujer y feminista) cómo esas voces del indio, del mestizo y del criollo no son relegadas del todo al silencio, pues éstos, con una posible toma de posición, de tomar el lugar del yo imperial o

\footnotetext{
${ }^{4}$ Josefina Ludmer teoriza cómo en el caso de Sor Juana Inés de la Cruz su discurso está articulado por una serie de tácticas que constituyen prácticas de resistencia frente al poder. En "Orden dogmático y marginalidad en la “Carta de Monterrey"” Mabel Morafía demuestra el proceso del desmontaje del mecanismo autoritario por parte de Sor Juana.
} 
de crear un espacio para su propia identidad criolla, amenazan con "posicionarse", imponerse y apropiarse del discurso dominante patriarcal y del lugar del sujeto imperial en ese discurso oficial en la colonia. Esa presencia ausente se interpone como suplemento amenazante y peligroso, como un grito estridente silenciado. Desde esta perspectiva, en Ruiz de Alarcón el discurso colonial es el suplemento que complementa su carácter diferencial y que descentra, re-emplaza y des-plaza al discurso imperial. El discurso colonial alarconiano es la presencia de la ausencia que llena el abismo de la significación de su singular "extrañeza". Es la plusvalía de la otredad marginal y monstruosa que brilla por su ausencia pero que está presente metonímicamente refiriendo a lo no-dicho.

En tales circunstancias, Ruiz de Alarcón, siendo el yo que es otro que se viste con el ropaje retórico imperial y se mira a imagen y semejanza del yo imperial, provoca a los críticos una crisis en la determinación del discurso colonial. Se les hace imposible leer el discurso colonial por la indeterminación histórico referencial y la ausencia de la representatividad autóctona en las comedias. Esa falta de evidencia textual, tanto de la topografía referencial histórica como de la tropos-grafía retórica discursiva colonial, me llevará a deslizarme por la red de articulaciones culturales discursivas e inter-textuales de la época en la re-presentatividad imaginaria de la otredad racial en los discursos imperiales. Mi fin último será hacer una lectura alternativa, política y descolonizadora de la comedia de moros y cristianos La manganilla de Melilla de Ruiz de Alarcón. Mediante esta lectura demostraré y recuperaré su condición colonial, su posición de sujeto colonial y su sistema retórico y discursivo de escritor indiano asimilado.

Comenzaron las conquistas de indios acabada la de los moros, porque siempre guerreasen españoles contra infieles ...5

Francisco López de Gómara

El año de 1492 simboliza ya, en la historia de España, este doble movimiento: en ese mismo año el país repudia a su Otro al triunfar de los moros en la última batalla de Granada y al forzar a los judíos a dejar su territorio, y descubre al Otro exterior, toda esta América que habrá de volverse latina (57).

Tzvetan Todorov

Es un factor histórico que con anterioridad a la Conquista de América en España se efectuó la Reconquista, y de hecho se ha señalado que la Conquista fue consecuencia, extensión y continuación de la Reconquista. A partir del encuentro de Colón, en este contexto, se da una re-activización religiosa y política y una transposición geográfica, racial y étnica de prácticas imperialistas en la que moros e indios aparecen como dos signos que en la tropos-grafía retórica y discursiva imperiales tienen unas mismas significaciones ideológicas, unas análogas funciones semánticas y connotaciones semióticas.

\footnotetext{
s Citado por Rolena Adorno en "El sujeto colonial y la construcción cultural de la alteridad" (58).
} 
Indios y moros son configurados y estereotipados como bárbaros, infieles, idólatras, herejes, agentes diabólicos, mentirosos, sospechosos e inferiores, que deben ser cristianizados, catequizados y civilizados a imagen y semejanza del imperio. Sus territorios deben ser ocupados, dominados y controlados por el sistema del poder y del saber, y por las instituciones y los agentes imperiales. Así, al moro y al indio se les sujeta sígnicamente y significantemente, se les objetiviza y se les adjudica un significado imperial que vacía su significación histórica propia. Al sujeto conquistado y subalterno se le a-signa una posición político ideológica para sujetarlo según los valores, creencias, convenciones, percepciones, actitudes, juicios y prejuicios regularizados, articulados y codificados por la cosmovisión imperialista y sus prácticas de saqueo y expansionismo. ${ }^{6}$

Desde sus principios la representación retórica en los discursos imperiales de la otredad racial y étnica, en el caso de América, se da por la semejanza: el indio obtiene su significación por la analogía con el moro y con todo el bagaje de la experiencia político-cultural no sólo del moro sino también del judío en la península. El proceso de colonización interna de asimilación, conversión y expulsión del moro y del judío, que también se extiende a la Conquista externa del guanche en las Canarias, y hasta a "la conquista mítica" del negro africano y del turco, se transplanta al Nuevo Mundo, haciendo del indio uno más de esos sujetos reconquistados y conquistados, o por conquistar, por la España cristiana. En tales circunstancias, en las cartas del Descubrimiento y en las crónicas de la Conquista (textos semióticos culturales) el indio pasa a ser el moro, y su re-presentatividad imaginaria se da por sustitución metafórica y por deslices metonímicos con el moro.

Para el descubridor y conquistador cristiano, Reconquista/Descubrimiento/Conquista se inter-conectan ideológica e históricamente con la toma de Granada en 1492, meses antes de Colón emprender su primer viaje: “... este presente año de 1492, después de Vuestras Altezas aver dado fin a la guerra de los moros, que reinavan en Europa, y aver acabado la guerra en la muy grande ciudad de Granada ..." (15) y ese mismo año, el 26 de diciembre, Colón combina ambos proyectos de Reconquista y Conquista:

Y dize qu'espera en Dios que, a la buelta que él entendía hazer de Castilla, avía de hallar un tonel de oro, que avrían resgatado los que avía de dexar, y que avrían hallado la mina de oro y la especería, y aquello en tanta cantidad que los Reyes antes de tres años emprendiesen y adereçasen para ir a conquistar la Casa Sancta, 'que así', dize él, 'protesté a Vuestras altezas que toda la ganancia d'esta mi empresa se gastase en la conquista de Hierusalem' (101).

Colón une la anhelada conquista de Jerusalén, iniciada por las cruzadas en la época medieval, con el sacamiento de riquezas, que pagaría la conquista de las tierras recién descubiertas. Al converger moros e indios en ambos discursos de Reconquista y Conquista, Granada-

\footnotetext{
${ }^{6} \mathrm{La}$ representación del moro en la literatura española apenas comienza a ser estudiada. Entre los trabajos críticos que han contribuido a mi teorización de la relación de moros e indios son de vital importancia "Other Fashioning" de Allen Carey Webb y "The Moor in the Text" de Israel Burshatin. Rolena Adorno en "Nuevas perspectivas" plantea que hace falta considerar Portugal y África en los estudios literarios coloniales. Véase su ensayo "La ciudad letrada y los discursos coloniales" donde se estudia la situación de los moriscos, y cómo moriscos y amerindios compartían experiencias históricas similares.
} 
Jerusalén-Nuevas Indias instituyen una línea discursiva inter-textual articulada por la subyugación racial y la misión imperial cristianizadora. Los indios como los moros (y los turcos), por herejes e idólatras, deben ser hechos sujetos cristianos bajo el poder imperial expansionista que procuraba no únicamente acrecentar la santa religión cristiana sino apoderarse de rutas comerciales y acumular oro, especierías y tierras. Con su declaración de cómo el oro de Indias podría beneficiar la Reconquista de Jerusalén, Colón traza un nuevo mapa imperial con su centro en la corte monárquica castellana, con la toma de Granada que delinea la nueva frontera castellana, con nuevas tierras en el Nuevo Mundo por cristianizar, con este mapa todo el imperio se entrecruza en una red cuyo pseudocentro es Jerusalén. ${ }^{7}$ A la vez Jerusalén es el epicentro de la retórica discursiva cristiana imperial y la razón para conquistar y dominar a la otredad satánica musulmana, conquista que se aseguraría con la ganancia del oro de Indias.

No caba duda que esos signos, moros e indios, se entre-cruzan e inter-cambian desde Colón en la praxis imperial. De ahí que Santiago, patrón de España en la guerra contra los moros, en vez de pasar a ser Santiago Mataindios en América sigue siendo literalmente Santiago Matamoros como lo atestiguan los nombres de ciudades y pueblos llamados Santiago y Matamoros en Cuba, República Dominicana, México, Pánama, Perú, Chile, étc. ${ }^{8}$ Ahora bien, en las artes plásticas, el vencido pisado por el caballo de Santiago ya no es un moro sino un indio, como puede evidenciarse con el retablo en el altar del Templo de Santiago en la "Plaza de las tres culturas" en México o con el dibujo 162 de Guamán Poma en Nueva Corónica y buen gobierno en el que Santiago con el caballo aplasta a un indio:

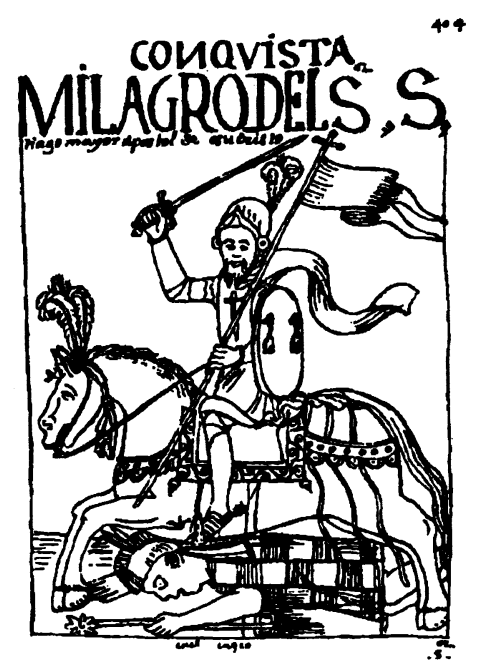

\footnotetext{
${ }^{7}$ Véase "The Movable Center" de Walter Mignolo donde examina los mapas de América en sus coordenadas ideológicas según la visión de mundo imperial.

${ }^{8}$ En América, según Marc Simmons, Santiago intervino como protector de los españoles por lo menos en unas trece ocasiones. Según él: "Spaniards gave eighty-one settlements in New Spain
} 
Tampoco podemos olvidar que en las representaciones de moros y cristianos del teatro evangelizador en la Nueva España, desde el siglo XVl hasta nuestros días, los moros eran y siguen siendo indios. ${ }^{9}$ El mejor ejemplo del teatro misionero y evangelizante del XVI lo es el relato de Fray Toribio de Benavente "Motolínia" en Historia de los indios de la Nueva España. ${ }^{10}$ El capitulo XV narra una fiestas de Corpus Christi, celebradas en Tlaxcala en 1538, en las que se representó La Conquista de Jerusalén. Los indios, haciendo de moros, habían de ser vencidos y bautizados como soldados de Cristo al final del "auto sacramental". En la representación en suelo novohispano la historia medieval de la Conquista de Jerusalen por Godofredo en 1099 se traslada al presente histórico con la Conquista de México: los infieles, moros e indios, tienen, en este sentido, el mismo papel en las tablas históricas imperiales. Para el sujeto español y su ojo imperial, moros, turcos $o$ indios son referentes con una misma significación y función, como lo serían los habitantes de las Filipinas donde también se propagó el espectáculo religioso de moros y cristianos por los misioneros.

Así, Reconquista/Descubrimiento/Conquista confluyen en la praxis imperial en su sumisión del otro racial y culturalmente diferencial. No es cuestión sólo de una nueva Reconquista en América, sino de que el indio mismo, por su diferencia racial es leído como continuidad africana, al igual que al nuevo espacio americano se superimpone y proyecta Andalucía o Canarias. Por ejemplo, Colón expone el primer encuentro racial de la siguiente manera: "Dellos se pintan de prieto, y dellos son de la color de los Canarios, ni negros ni blancos"; "ellos ninguno prieto, salvo de la color de los canarios, ni se deve esperar otra cosa, pues está Lestegüeste con la isla del Fierro en Canaria, so una línea" (31). Esa línea también es el eje sintagmático centralizador, e ideológico, que permite la articulación del espacio de las tierras recién descubiertas en comparación a Sevilla y Córdoba, a todos los campos y ríos de Andalucía, que era tierra de moros. De ahí que Colón lea los templos de los indios como mezquitas: "y una dellas (montaña) tiene ençima otro montezillo a manera de una hermosa mezquita" (47); y que compare lo visto al mundo árabe conocido en la península: "todos se fueron a tierra con sus almadías" (32); "eran hechas amanera de alfaneques" (46); "veyendo tanta verdura entanto grado como en el mes de Mayo en el Andaluzía" (38); "y las noches temperadas como en Mayo en España, en el Andaluzía" (43). Tal como el templo arquitectónico musulmán pasa a ser el referente de la otredad antes vista y mediatiza en el presente de lo que se ve como antes visto y diferente, también el indio por su diferencia racial tiene como referente al moro. Debido al modo imperial de ver las cosas, y de nombrarlas por semejanza, Colón incluso pretende

(modern Mexico) the name Santiago" (17). Simmons también observa que en una que otra ocasión los indios aparecen bajo la protección de Santiago contrario a la representación tradicional de indios vencidos por el Apóstol. Sobre el tema consúltense los trabajos de Rafael Heliodoro Valle y Elizabeth Wilder Weismann.

${ }^{9}$ La bibliografia es vasta sobre el tema; recomiendo los trabajos de John E. Englekirk, Gisela Beutler y Frances Gillmor para quien se interese en las representaciones tradicionales en América de "Moros y Cristianos".

${ }_{10}$ Othón Arróniz en Teatro de evangelización en Nueva España, capítulo V "La primera pieza teatral mexicana: 'La Conquista de América"' presenta un buen resumen con documentación histórica sobre la representación teatral. 
comunicarse con los indios en hebreo o árabe a través de un traductor: "Un Luis de Torres, que avía bivido con el Adelantado de Murcia y avía sido judío y sabía diz que ebraico y caldeo y aún algo arávigo" (50). Y, de hecho, en su cuarto viaje todavía los moros y la lengua árabe siguen siendo el referente de la alteridad lingüística, racial y cultural: "Los pueblos ... cada uno tiene diferençiada lengua, y es en tanto que no se entienden los unos con los otros más que nos con los de Aravia" (326).

Partiendo de las premisas anteriores y volviendo a Ruiz de Alarcón, por eso de hacer conjeturas, propongo que de haber escrito el dramaturgo sobre el indio sólo habría podido echar mano al discurso del poder imperial en la re-presentación de la otredad racial indígena (y del moro). Me viene a la mente La araucana como modelo ideal para este dramaturgo que procuraba insertarse en el poder de la ciudad letrada colonial e imperial. Y mi idea no resulta tan descabellada, pues Ruiz de Alarcón con otros ocho dramaturgos en 1622 escribió la primera escena del segundo acto de una comedia sobre la conquista de los araucanos ("los indomables bárbaros de Chile"), Algunas hazañas de las muchas de Don Garcia

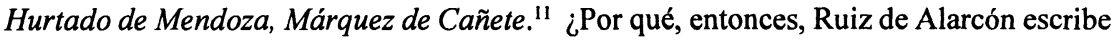
en conjunto sobre el Nuevo Mundo? ¿Por qué no quiere asociarse individualmente con la realidad colonial? ¿Acaso escribe esta obra en conjunto por conveniencias de mecenazgo y de conexciones con la administración de la corte virreinal de acuerdo a sus esperanzas de volver a la Nueva España con un puesto burocrático? Podemos asumir que por ser Ruiz de Alarcón de descendencia netamente castellana y por estar inmaculado de toda mancha de posible mestizaje, no se identifica con el "indio feo" ni se interesa en la puesta en escena del indio. Al contrario, de "salírsele el indio" (pues sólo se le sale levemente en esta comedia sobre los araucanos) se problematizaría su condición de nobleza. De ahí que procure probar una y otra vez su hidalguía, su linaje y su limpieza de sangre. Un memorial de 1635 (como también lo hacen los galanes en sus comedias) evidencia esa obsesión de abolengo de descen-dencia castellana:

Es hijo lejitimo de Pedro Ruiz de Alarcon y doña Leonor de Mendoza que fueron mineros de las de Tasco y nieto de Hernando Hernandez de Caçalla y doña Maria de Mendoça hijosdalgo notorios y de los primeros pobladores de la Nueva España a donde ha mas de sententa años ... ${ }^{12}$

Dado que Ruiz de Alarcón se considera tan español como los peninsulares, su cosmovisión está enmarcada por los parámetros sociales e ideológicos imperiales. Como buen asimilado, lee la Nueva España desde los discursos imperiales del poder, y es en este contexto que podemos ubicar su comedia de moros y cristianos, LMdeM. Si el espacio autóctono, como señalé antes, está ausente en sus comedias, se debe también a que en el discurso dramático de la época figura un vacío de la puesta en escena de la Conquista y Colonización del Nuevo Mundo. ¿Se debió tal vacío a la leyenda negra? En el siglo XVII

\footnotetext{
"La obra está incluida en la edición de las comedias de Ruiz de Alarcón por Agustín Millares Carlo. Ver Luis Fernández Guerra y Orbe quien ofrece datos históricos sobre Hurtado de Mendoza y contribuye con observaciones sobre la escritura de la obra.

12 Ver "Memorial de mis servicios", documento VII, 84-85, en Apuntes y documentos nuevos para la biografia de Juan Ruiz de Alarcón y Mendoza.
} 
sólo dos comedias, El Descubrimiento del nuevo mundo por Cristobal Colón y El arauco domado de Lope de Vega, constituyen el parangón teatral de la empresa descubridora y conquistadora. ${ }^{13}$

Si Ruiz de Alarcón quería ser aceptado y pasar por español a toda costa, ¿por qué poner sobre el tapete su lugar de origen, su diferencia natural y nativa de ser "natural de Indias", "criollo de México", "indiano", o "perulero"? Sin tener otra alternativa, Ruiz de Alarcón opta por imitar, adoptar y adaptar los modelos dramáticos dominantes; sobre todo tiene a su disponibilidad el escribir una comedia de moros y cristianos. Y en efecto, escribe una comedia sobre la conquista de Melilla en el norte de Africa, LMdeM. En esta obra nos coloca en la periferia y nos sitúa en el mapa cultural y religioso del teatro evangelizador y en el imaginario colectivo de la Nueva España. Se trata de una obra que nos hace delinear una topografia imperial de un espacio colonial y de sus agentes raciales y étnicos propios - África/moros-, y que nos conecta por relación paradigmática con Indias/indios y con el teatro evangelizador de moros y cristianos. Por medio de la sustitución metáforica y los deslices metonímicos en los discursos imperiales que he señalado anteriormente, y a base de la relación que se establece entre moros e indios, se puede teorizar respecto al proceso de una toma de posición de sujeto asimilado por parte del colono Ruiz de Alarcón. En tal sentido, LMdeM coloca a Ruiz de Alarcón en las encrucijadas periféricas del mapa imperial una vez que en el desdoble del espacio africano subyace el espacio indiano como otredad geográfica, cultural, étnica y racial. Siguiendo esta línea topográfica -iniciada por Colón- de África a Indias, propongo que por el intercambio sustitutivo, la inicial ausencia de un referente en la línea geopolítica sintágmatico-imperial complementa y llena de significación ulterior a dicho referente ausente en el teatro colonial de Ruiz de Alarcón. Por consiguiente, en este juego de espejos, de re-emplazamientos y relaciones referenciales, Africa se convierte en $L M d e M$ en el espacio fronterizo y colonial, supletorio de la Nueva España en la escritura del dramaturgo. A través de esta lectura ex-céntrica, la extensión geográfica imperialista de las colonias se convierte en un espacio in-diferencial en el que pueden llenarse los blancos de las colonias ausentes en el texto dramático con el nombramiento de una sola de éstas - Melilla, y por contigüidad Ceuta, Canarias, Indias, Nueva España, Perú. A pesar del deslizamiento de la referencia, el contexto histórico y político sigue siendo el mismo para el centro imperial. Es decir, la función referencial no cambia en su significación: una colonia es una colonia es una colonia... En el desplazamiento metonímico sólo se da un tras-lado de significantes mediante un proceso de transferencia que para el imperio no cambia ni su función, ni su significación, ni su relación de poder imperial.

Si Ruiz de Alarcón se sirve de la tropos-grafia retórica discursiva imperial para representar la otredad racial del moro, su selección del modelo de comedia de moros y cristianos, en mi lectura alternativa, es el punto de sostén, primeramente para demostrar la posición alarconiana en el discurso literario hegemónico imperial, y segundo para señalar cómo en el funcionamiento del eje sintáctico que subrepticiamente propone el imperio ante las relaciones referenciales referentes a las colonias, el deslizamiento de África a

\footnotetext{
${ }^{13}$ Veáse el artículo de Glen F. Dille "El Descubrimiento y la Conquista de América en la comedia del Siglo de Oro".
} 
Indias revela un desplazamiento metonímico que es una puesta en escena tras bastidores de la condición colonial y del sujeto alarconiano. Tal sustitución, o mejor dicho, tal paradigma fugaz, desdobla en el espacio africano el espacio indiano, llenándose ambos de significaciones complementarias y suplementarias, "in praesentia" e "in absentia". Por ende, el Nuevo Mundo deja de ser un signo flotante en el vacío referencial novo-hispano de la escritura dramática alarconiana. No más hay que trazar la extensión geográfica colonial del imperio español, de África a Indias, para que ambos espacios sean dos referentes que tienen una misma significación para el ojo castellano centralizador y su mirada etnocéntrica y racista imperial (como vimos en el diario de Colón).

Mas, Indias no es un lapsus geográfico en LMdeM. El Nuevo Mundo emerge, irrumpe e interrumpe el texto en dos ocasiones: ${ }^{14}$

Azen: ... y si codicias riquezas, por estas nuevas cuantas las Indianas cuevas, rinden te daré en albricias; (201).

Azen: Cuantas riquezas estima el Indio avaro tendrás ... (212).

Estas referencias a Indias abren en el texto una relación con la condición colonial alarconiana. El espacio indiano y el indio se hacen visibles para volver a ser in-visibles en el resto de la obra. En estas citas se concibe las Indias como fuente de riquezas y esas riquezas que le pertenencen al indio le serán arrebatadas. Por otro lado, el indio es definido peyorativamente por la cualidad de la avaricia, transponiéndose así al indio oprimido la reconocida y divulgada noción de la codicia del español. ¿Y por qué se lleva a cabo tal transposición? Digamos primero que nada que porque el hablante es Azen, un moro bárbaro y cruel, quien perturba el orden en la comedia. Y segundo, porque Azen en su ofrecimiento de riquezas indianas amenaza y usurpa el orden imperial, ¿un moro extrayendo riquezas de América? En este contexto el moro funciona como opresor del indio y como una especie de ladrón de los tesoros mineros del Nuevo Mundo. Y tercero, digamos que al transferirse al "indio avaro" la sobre-estimación de riquezas, en vez de leer el "español avaro", queda circunscrito el signo moro, por su condición de insurgente, a las coordenadas discursivas estereotípicas de la barbarie según lo define el poder imperial y lo fija en su tropos-grafia retórica etnocéntrica e imperial. En tales circunstancias, tanto el pronunciamiento y posición de Azen como la ausencia del indio, en el discurso dramático alarconiano, están moldeados por el estereotipo dominante de la alteridad —del moro y del indio bárbaro. Más aún, al ofrecer Azen riquezas, dinamita su propia persona y su acto de piratería. De este modo, la ideología dominante y la articulación literaria de la alteridad en la red de configuraciones, significaciones y restricciones ideológicas, según sus juicios y prejuicios, no permiten la aparición lingüística de lo que podría ser la naturaleza insolente de "español avaro", pero sí dan acceso a las de "indio avaro".

Sin embargo, la emergencia de "Indias" en el texto re-vela una especie de lapsus lingue alarconiano, una necesidad de nombrar Indias sin poder tener control lingüístico, bien podemos decir que no más se le sale el vocablo. Esos brotes lingüísticos espontáneos

\footnotetext{
14 Las citas de la comedia provienen de la edición de Millares Carlo.
} 
y resurgimientos momentáneos de "Indias", esa especie de tartamudeo, evidencian un exceso semiótico de la otredad colonial alarconiana, y, una vez pronunciados, ¿no conscientemente?, se vuelven a sumergir bajo la superficie del texto para pasar a ser mediaciones y desplazamientos metafóricos. Aún más, la condición colonial se suspende en una vacuidad referencial que da significación por cualidad suplementaria. En esta situación discursiva, en el proceso de la enunciación, la distante y desplazada Indias en $L M d e M$ no es irrevelante, ni accidental. "Indias" se cuela como enunciado para deslizarse a la in-significación. Después de ser nombrada, "Indias" vuelve a ser in-significante, pasa a ser in-diferencia.

"Indias" en el discurso dramático alarconiano se revela como una presencia que es a la misma vez ausencia y que pretende llenar un vacío innombrable. "Indias", en $L M d e M$, no puede cerrar su significación con lenguaje porque no lo hay: el signo con diferente sentido y función aún no ha sido gestado ni gesticulado por el criollo. Hay que esperar hasta la emergencia de una conciencia diferencial en Juan de Espinosa Medrano (El Lunarejo), Sor Juan Inés de la Cruz, Sigüenza y Góngora, o hasta el sujeto mestizo del Inca Garcilaso. ${ }^{15}$ En Ruiz de Alarcón "Indias" como lenguaje propio y como enunciación propia y representatividad corresponde a un estado de afasia de la identidad colonial que limita la posibilidad discursiva y la subjetividad del indiano asimilado que es Ruiz de Alarcón. La facultad de hablar, de expresarse y representarse a nivel de tanto de discurso, de lenguaje, como de imagen, y en el dominio retórico y discursivo del sujeto colonial desde/en una auto-representación, es inexistente. El indiano, como Ruiz de Alarcón en $L M d e M$, sólo puede representarse por medio del repertorio cultural e imperial de la otredad colonial. Su capacidad lingüística y retórica en esta fase de la identidad criolla, aún no formada, se limita a la re-producción de re-presentaciones y discursos prefabricados por el yo imperial y su modo de ver las cosas.

Es irónico que $L M d e M$, una comedia en que Ruiz de Alarcón presenta y articula la cuestión imperial en su relación de conquistador/conquistado, de la otredad racial sometida al sujeto coherente cristiano, haya quedado fuera del canon peninsular y colonial, y quede relegada al margen, al silencio y al olvido.

$L M d e M$, incluida en la Segunda Parte de las comedias alarconianas publicada en 1634 , ha sido reeditada sólo en ediciones de las obras completas. ${ }^{16}$ Tampoco la crítica se ha detenido ni concentrado en el estudio crítico de esta desafortunada comedia. ${ }^{17}$ Juan E. Hartzenbusch en su "Prólogo" a la edición de las comedias en Biblioteca de Autores

\footnotetext{
${ }^{15}$ Para una teorización del sujeto colonial y la formación de la identidad criolla, veánse los trabajos de Mabel Moraña.

${ }^{16}$ Ver Hartzenbusch, Ebersole y Millares Carlo.

${ }^{17}$ Sobre la comedia sólo se han hecho comentarios o estudios temáticos y estilísticos. Ver Castro Leal (88-92); Millares Carlo (181-183); Walter Poesse (64-66); y Ellen Claydon (Capítulo II "Religious Spectacle Plays"). Los artículos de Serrano Castilla y Bacaicoa Arnaiz son estudios superficiales de $L M d e M$.
} 
Españoles en 1852, publicación que canonizaría definitivamente a Ruiz de Alarcón en las letras peninsulares, comenta brevemente sobre LMdeM:

En LMdeM, especie de comedia de magia, una de las menos recomendables de nuestro poeta, después de la del Anticristo, se halla este vigoroso diálogo entre un caudillo español y un moro:

$\begin{array}{ll}\text { Azen: } & \text { ¿Quieres por una mujer } \\ & \text { Perder la vida y honor? } \\ \text { Vanegas: } & \text { Moro, yo gento valor } \\ & \text { Que no teme tu poder; } \\ & \text { Y aunque toda Berbería } \\ & \text { Venga talando y rompiendo, } \\ & \text { La causa de Dios defiendo, } \\ & \text { Y él defenderá la mía (XXII). }\end{array}$

Hartzenbusch reconoce y advierte la mala calidad de la obra: no puede alabarla por estar mal escrita, ni puede colocarla al mismo nivel estético del resto de la producción dramática alarconiana que, según él, "aventaja sin excepcion á todos en la variedad y perfeccion de las figuras, en el tino de manejarlas, en la igualdad del estilo, en el esmero de la versificacion, en la correccion del lenguaje." (XVII) Por ser LMdeM "una especie de comedia de magia", cae en un espacio liminal del ni esto ni lo otro, siendo así definida como un género híbrido que raya en la monstruosidad. La obra que pertenece al género de comedia de moros y cristianos queda fuera de dicha categorización. Al evadir toda clasificación, por su rareza se le compara con El Anticristo, otra mala comedia del dramaturgo. Hartzenbusch se limita a rescatar un trocito del texto en el que el capitán Vanegas se enfrenta al moro en superioridad imperial, humana y espiritual, como héroe épico de quien irradia una red de ideologemas castellanos: honor, valor, poder y defensa del cristianismo. Con esta valoración, Hartzenbusch hace en Ruiz de Alarcón una lectura auto-reflexiva y especular de su bagaje cultural español que confirma a priori la proyección asimiladora española e imperial del dramaturgo. Es decir, a través del sistema de valores del capitán español, Hartzenbusch rescata su propia imagen cultural española proyectada en la escritura alarconiana.

En el apéndice de la edición, Hartzenbusch incluye una serie de "Artículos críticos acerca de las obras de Don Juan Ruiz de Alarcón", y entre éstos José Amador de los Ríos comenta sobre unos versos de $L M d e M$ :

\section{Alima: Cual timido pajarillo que cuando el viento retumba, etc.}

Estos versos tienen toda la gala, llenura y armonía de que son capaces aun los mejores aconsonantados o endecasílabos (525).

Amador de los Ríos detecta en la escritura alarconiana el uso del lenguaje poético y de la métrica castellana para situar el estilo, la retórica y la versificación alarconiana a la altura de la excelencia del corpus poético renacentista y barroco españoles. Esa preocupación por comprobar una métrica castellana en Ruiz de Alarcón evidencia el esmero de los filólogos decimonónicos de verificar la calidad española en la escritura alarconiana. Para ellos, lo 
importante de por sí es demostrar que Ruiz de Alarcón sabe escribir, que maneja las técnicas retóricas y la elegancia estilística del Barroco, es decir, del discuro imperial, y que posee tanto la corrección y la belleza de la expresión del lenguaje castellano como la destreza en el uso de la versificación que requiere el endecasílabo. Pero, ¿son endecasílabos los versos citados? No. Por eso, tal aseveración, es mas bien consecuencia del deseo de los críticos por dejar demostrado el castellanismo alarconiano en su afán de eludir, descartar, de echar de lado, su origen colonial. A medida que se centran sólo en la lectura del discurso imperial, no hay duda que los críticos mantienen una posición purista, de índole imperialista, para bregar con la cuestión colonial de Ruiz de Alarcón. El saber escribir y el escribir a perfección se convierte en una de las características de la que se adhieren los críticos para canonizarlo como dramaturgo del Barroco desde 1826: "Pero en lo que es sobresaliente Ruiz de Alarcon, es en el lenguaje. Ningún escritor español le ha poseido con más pureza, propiedad y corrección. No tememos asegurar que es uno de los mejores, sino es el primero de los hablistas castellanos. Es un modelo que debe estudiarse continuamente" (Ruiz de Alarcón, Comedias ... 122, palabras del editor).

Irónicamente, los filólogos no consideraron que ese purismo desdobla y apunta a la escritura de un asimilado colonial, de que esa ultra-correción y propiedad alarconiana es la marca textual de su modalidad autorial colonial. Ese registro lingüístico y estilístico de "pureza, propiedad y perfeccion" constata su dominio y apropiación del lenguaje y la retórica discursiva imperiales. Los filólogos decimonónicos, como los "scholars" de la academia anglo-americana de este siglo, no se percataron de que el purismo alarconiano trata del saber decir y del escribir con autoridad con todos los derechos de autor, de autoría y de autoridad legitimados por el poder imperial al colono en la corte virreinal (de donde provenía Ruiz de Alarcón). ${ }^{18}$ Pero la verdad es que $L M d e M$ no se puede elogiar: ni es una perla estilística ni un tesoro retórico. Al contrario, es una mala comedia y por eso quedó marginada y olvidada. Digamóslo ya: $L M d e M$, comedia de moros y cristianos en su época pudo haber sido valorada como "oro del que cagó el moro", proverbio que encarna de por sí los prejuicios y el racismo del imperio hacia la otredad étnica, cultural y racial.

Considero de vital importancia, para leer el discurso colonial de Ruiz de Alarcón, su incapacidad para emplear la retórica y las técnicas dramáticas en el género de comedia de moros y cristianos. Podemos decir que tal ineficiencia infiere una falla en el dominio del discurso épico imperial por su parte. Bien observaron Fernández Guerra y Antonio Castro Leal respectivamente:

La comedia, que se pudiera clasificar de tramoya, con pretensiones de heroica, tiene por argumento y fin moral solemnizar el imperio de la fe cristiana y la virtud de la continencia (218).

\footnotetext{
18 Jaime Concha señala sobre el lenguaje barroco y el gongorismo en las colonias: "se pone al servicio de intenciones claramente apologéticas del orden colonial, especialmente de una superestructura administrativa civil y eclesiástica. Lo que en la metrópoli fue un impulso de liberación cultural llevado hasta límites extremos de las posibilidades del lenguaje, se convierte en la Colonia en un vehículo de poesía devota, de reverencia hagiográfica", 46.
} 
Su construcción es hábil; pero Alarcón renunció a la posibilidad de un tratamiento épico, al que se prestaba el famoso engaño o manganilla con que el general Pedro Venegas derrotó a las fuerzas de Ademahamet Bualat que quisieron entrar, inermes y confiadas, en las fortalezas de Melilla (1565) (91).

Por otro lado, el fracaso retórico también se descubre en el manejo imprudente, rechinante, postizo y casi paródico del estilo retórico gongorino en la comedia (por ejemplo, "a los aires oro en rayos/y a los campos plata en perlas ..." (185); "que dio Tálamo a Peleo/del sol las doradas trenzas" (187). Castro Leal mismo señala la artificialidad gongorina del dramaturgo:

Esta influencia decrece conforme avanza la comedia, y Alarcón vuelve, como quien se va librando de una obsesión, a una tonalidad fría y a un dibujo más tranquilo. Pero es notable el ritmo nervioso y tónico que la atracción de la opulencia gongorina imprime en aquellas primeras escenas, en que las palabras, cansadas de arder por combustión, se inflaman con reflejos coruscantes (91).

No hay duda que la imitación alarconiana de Góngora se torna en falsificación paródica, de que la réplica retórica sólo refleja y refracta la inautenticidad. Si aplicamos la sentencia de Umberto Eco "replica, no matter how perfect, is refused as a fake" (179), LMdeM es una mala copia del discurso épico dramático y de la retórica imperial, carece de autenticidad y de originalidad. Tal desfiguración caricaturesca revela una modalidad autorial de Ruiz de Alarcón que puede comprenderse sólo tomando su condición de escritor asimilado colonial. Esa diferencia es el asomamiento impertinente de la inautenticidad del colono que irrumpe, interrumpe y muestra el surgimiento de lo autóctono colonial que perturba y disturba el discurso oficial. El colono Ruiz de Alarcón y Mendoza que pretende una escritura heroica con LMdeM (como con El Anticristo) culmina en el fracaso artístico, fracaso que funciona como una especie de striptease y cuya escritura termina por descubrir su corpus discursivo colonial. A ese colono, el ojo imperial sólo lo reconoce como mala réplica, es decir, copia (no como acto contestatario). ${ }^{19}$ Hay que desautorizarlo por querer ser y no poder ser imagen y semejanza del original. El ojo imperial lo desnuda y lo descalifica al descubrir al colono disfrazado con su ropaje retórico imperial.

\section{OBRAS CITADAS}

Adorno, Rolena. "La ciudad letrada y los discursos coloniales". Hispamérica, Año XVI, 48 (1987): 3-24.

"El sujeto colonial y la construcción cultural de la alteridad". Revista de Crítica Literaria Latinoamericana, 28 (1988): 55-68.

"Nuevas perspectivas en los estudios literarios coloniales latinoamericanos". Revista de Crítica Literaria Latinoamericana, 28 (1988): 11-27.

\footnotetext{
${ }^{19}$ Para una teorización del discurso colonial como réplica, ver mi trabajo "Bases teóricas para una lectura ex-céntrica". En este trabajo propongo que los discursos coloniales deben ser leídos en su doble función de copia y de acto contestatario.
} 
Arróniz, Othón. Teatro de evangelización en Nueva España. México: Universidad Nacional Autónoma de México, 1979.

Bacaicoa Arnaiz, Dora. Notas hispano-marroquies en dos comedias del Siglo de Oro. Tetúan: Majzen, 1954.

de Benavente, Fray Toribio. Historia de los indios de la Nueva España. Madrid: Alianza Editorial, 1988.

Beutler, Gisela. "Algunas observaciones sobre los textos de 'Moros y Cristianos' en México y Centroamérica". Actas del VIII Congreso de la Asociación Internacional de Hispanistas. A. David Kossoff et al, editor. Madrid: Ediciones Istmo, 1986. 221233.

Burshatin, Israel. "The Moor in the Text: Metaphor, Emblem, and Silence". "Race", Writing, and Difference, Henry Louis Gates, Jr., editor. Chicago: University of Chicago Press, 1986. 117-137.

Carey Webb, Allen. "Other Fashioning: The Discourse of Empire and Nation in Lope de Vega's El nuevo mundo descubierto por Cristobal Colón". Amerindian Images and the Legacy of Columbus, René Jara y Nicholas Spadaccini, editores. Minneapolis: University of Minnesota Press, 1992. 425-451.

Castellanos, Rosario. "Juan Ruiz de Alarcón: Una mentalidad moderna". Anuario de Letras de la UNAM, 8 (1970): 147-172.

Claydon, Ellen. Juan Ruiz de Alarcón: Baroque Dramatist. North Carolina: Estudios de Hispanófila, 1970.

Castro Leal, Antonio. Juan Ruiz de Alarcón: Su vida y su obra. Méjico: Cuadernos Americanos, 1943.

Colón, Cristobal. Textos y documentos completos, Consuelo Varela, editora. Madrid: Alianza Universidad, 1984.

Concha, Jaime. "La literatura colonial hispano-americana: Problemas e hipótesis". Neohelicon, 4/1-2 Budapest, (1976): 31-50.

Dille, Glen F. "El Descubrimiento y la Conquista de América en la comedia del Siglo de Oro". Hispania, 71 (1988): 492-502.

Eco, Umberto. A Theory of Semiotics. Bloomington: Indiana University Press, 1976.

Englekirk, John E. "El teatro folklórico latinoamericano". Folklore Americas, XVII (June 1957): 1-36.

Fernández Guerra y Orbe, Luis. Don Juan Ruiz de Alarcón y Mendoza. Madrid: Rivadeneyra, 1871.

Fernández Retamar, Roberto. Calibán: Apuntes sobre la cultura en nuestra América. México: Diógenes, 1974.

Gillmor, Frances. "Spanish Texts of Three Dance Dramas from Mexican Villages". University of Arizona Bulletin, XIII/4 (1942).

Hartzenbusch, Juan E. Comedias de Don Juan Ruiz de Alarcón y Mendoza. "Prólogo". Madrid: Biblioteca de Autores Españoles, XX, 1852.

Henríquez Ureña, Pedro. "Don Juan Ruiz de Alarcón", conferencia pronunciada en México el 6 de diciembre de 1913. Habana: Imprenta El siglo XX, 1915.

Las corrientes literarias en la América Hispánica. México: Fondo de Cultura Económica, 1949. 
"El teatro en la América colonial". Obra crítica. Emma S. Speratti Piñero, editora. México: Fondo de Cultura Económica, 1960.

Ludmer, Josefina. "Tretas del débil". La sartén por el mango: Encuentro de escritoras latinoamericanas". Patricia E. González y Eliana Ortega, editoras. Puerto Rico: Ediciones Huracán, 1984.

Menéndez y Pelayo, Marcelino. Introducción, Antología de poetas hispanoamericanos. Madrid: Academia Española, 1893. Reimpresa bajo el título Historia de la poesía hispano-americana, Tomo I. Madrid: Librería general de Victoriano Suárez, 1911. Mignolo, Walter D. "The Movable Center: Geographical Discourses and Territoriality During the Expansion of the Spanish Empire". Encoded Encounters: Writing, Gender, and Ethnicity in Colonial Latin America, Francisco Javier Cevallos-Candau et al., editores. Amherst: University of Massachusetts Press, 1994. 15-45.

Moraña, Mabel. "Barroco y conciencia criolla en Hispanoamérica". Revista de Crítica Literaria Latinoamericana, 28 (1988): 229-251.

"Para una relectura del Barroco hispanoamericano: Problemas críticos e historiográficos". Revista de Crítica Literaria Latinoamericana, 29 (1989): 219231.

"Formación del pensamiento crítico-literario en Hispanoamérica: Epoca colonial". Revista de Crítica Latinoamericana, 31-32 (1990): 255-265.

“Orden dogmático y marginalidad en la 'Carta de Monterrey' de Sor Juana Inés de

la Cruz”. Hispanic Review, 58/2 (1990): 205-225.

"Máscara autobiográfica y conciencia criolla en Infortunios de Alonso Ramírez". Dispositio, XV/40: 107-117.

"Apologías y defensas: Discursos de la marginalidad en el Barroco hispanoamericano". Relecturas del Barroco de Indias. Hanover: Ediciones del Norte, 1994. 31-57.

Poesse, Walter. Juan Ruiz de Alarcón. New York: Twayne, 1972.

Poma de Ayala, Guamán. El primer nueva coronica y buen gobierno (1615). John V. Murra y Rolena Adorno, editores. México: Siglo XXI, 1980.

Ruiz de Alarcón y Mendoza, Juan. Obras completas, I-III. Agustín Millares Carlo, editor. México: Fondo de Cultura Económica, 1968. Obras completas de Juan Ruiz de Alarcón y Mendoza, Tomos I y II. Alva V. Ebersole, editor. New York: Estudios de Hispanófila, 1966.

Comedias escogidas de Don Juan Ruiz de Alarcón y Mendoza. Manuel Bernardino García Suelto, editor. Madrid: 1826.

Sandoval Sánchez, Alberto. Revista de Crítica Literaria Latinoamericana, número monográfico: Historia, sujeto social y discurso poético en la colonia, directora Mabel Moraña, Lima, Año XIV, 28 (1988): 281-290.

"Bases teóricas para una lectura ex-céntrica del discurso colonial de Juan Ruiz de Alarcón". Relecturas del Barroco de Indias. Hanover: Ediciones del Norte, 1994. 281-302.

Schons, Dorothy. Apuntes y documentos nuevos para la biografia de Juan Ruiz de Alarcón $y$ Mendoza. Chicago: The University of Chicago Libraries, 1929.

Serrano Castilla, Francisco. "Coincidencias entre dos obras del teatro español del siglo XVII". Archivum, Oviedo, 22 (1972): 473-487. 
Simmons, Marc. "Santiago: Reality and Myth". Santiago: Saint of Two Worlds. Albuquerque: University of New Mexico Press, 1991. 1-29.

Spivak, Gayatri Chakravorty. In Other Worlds: Essays in Cultural Politics. New York: Methuen, 1987.

Todorov, Tzvetan. La conquista de América: La cuestión del otro. México: Siglo XXI, 1987.

Valbuena Prat, Angel. Historia de la literatura española. Barcelona: Gustavo Gil, tomo II, 1968. 503-524.

Historia del teatro español. Barcelona: Noguer, 1956. 187-203.

Valle, Rafael Heliodoro. Santiago en América. México: Editorial Santiago, 1946.

Weismann, Elizabeth Wilder. Mexico in Sculpture: 1521-1821. Cambridge: Harvard University Press, 1950. 
. 